\title{
MONITORING ELEKTROKARDIOGRAF MENGGUNAKAN TOPOLOGI MESH
}

\section{ELECTROCARDIOGRAPH MONITORING USING MESH TOPOLOGY}

\author{
Sugondo Hadiyoso ${ }^{1}$, Ratna Mayasari ${ }^{2}$ \\ ${ }^{1}$ Prodi D3 Teknik Telekomunikasi, Fakultas Ilmu Terapan, \\ Universitas Telkom \\ ${ }^{2}$ Prodi S1 Teknik Telekomunikasi, Fakultas Teknik Elektro, Universitas \\ Telkom \\ 1ugondo@telkomuniversity.ac.id, ratnamayasari@telkomuniversity.ac.id
}

\begin{abstract}
Abstrak
Penerapan wireless sensor node (WSN) telah banyak dikembangkan untuk aplikasi monitoring parameter kesehatan pasien, salah satunya digunakan pada perangkat elektrokardiogram. Pada penelitian sebelumnya, dibuat sistem monitoring EKG menggunakan topologi multipoint to point berbasis perangkat transceiver Xbee[1]. Sistem tersebut menggunakan tiga node sensor dengan satu node kordinator sebagai penerima data dari semua node sensor. Pada topologi tersebut, tidak terdapat node yang difungsikan sebagai router sehingga tidak ada rute alternatif jika terjadi kesalahan pada suatu node. Selain itu, tidak dapat digunakan untuk jarak transmisi yang lebih jauh. Solusi permasalahan tersebut adalah dengan mengaplikasikan topologi jaringan mesh. Sistem ini digunakan untuk aplikasi monitoring EKG secara real time yang terdiri dari 4 buah node sensor. Dimana 3 buah node sensor berfungsi sebagai router, 1 buah node sensor sebagai end device dan 1 buah kordinator pada bagian penerima sebagai pusat pengolah data. Dari hasil pengujian diperoleh bahwa data dari setiap node sensor diterima dengan baik. Penambahan karakter diperlukan untuk identifikasi sumber node. Proses routing berjalan dengan baik ketika ada node yang mengalami gangguan.
\end{abstract}

Kata kunci: Wireless, EKG, monitoring, XBee, mesh

\begin{abstract}
Application of wireless sensor node (WSN) has been developed for application monitoring patient health parameters, one of which is used in the electrocardiogram. In previous research, has made an ECG monitoring system using a multipoint-to-point topology based XBee transceiver devices [1]. The system uses three sensor nodes with a coordinator node as a receiver of the data from all the sensor nodes. In this topology, there are no nodes that function as a router so that there is no alternative route in case of an error in a node. Moreover, it can't be used for further transmission distance. The solution to these problems is applying a mesh network topology. This system is used for applications in real time ECG monitoring which consists of 4 sensor nodes. The function of Three sensor nodes as router, 1 sensor nodes as end devices and 1 coordinator at the receiver as a data processing center. From the test results obtained that the data from each sensor node received. The addition of characters needed to identify the source node. Routing process works well when there is a node with problems
\end{abstract}

Keywords: Wireless, EKG, monitoring, XBee, mesh 


\section{PENDAHULUAN}

Wireless Sensor Node (WSN) merupakan salah satu teknologi yang dapat digunakan pada aplikasi monitoring secara jarak jauh. WSN umumnya direalisasikan menggunakan beberapa modul transmisi nirkabel seperti wireless LAN, bluetooth dan Xbee. Salah satu penerapan WSN adalah aplikasi monitoring parameter kesehatan pasien jantung menggunakan elektrokardiograf pada rumah sakit. Pada penelitian sebelumnya, direalisasikan suatu sistem monitoring EKG untuk multiuser[1] dengan sebuah perangkat penerima. Tidak terdapatnya modul router pada sistem tersebut menyebabkan tidak adanya jalur alternatif jika pada salah satu perangkat terjadi kesalahan. Selain itu, jarak pengiriman maksimum yang diperoleh tidak lebih dari 60 meter. Permasalahan tersebut dapat diatasi dengan mengaplikasikan suatu jaringan Mesh yang diterapkan pada aplikasi monitoring EKG untuk multiuser.

Pada penelitian ini, direalisasikan suatu sistem aplikasi monitoring EKG multiuser menggunakan topologi jaringan Mesh. Sistem ini terdiri dari 4 buah node sensor yang masingmasing berfungsi untuk mengakuisisi sinyal EKG pasien. Selain fungsi tersebut, 3 node yang masih merupakan bagian dari sistem, berperan sebagai router untuk menjalankan fungsi routing. Modul transmisi yang digunakan untuk membuat aplikasi ini adalah XBee series 2. Dipilihnya modul tersebut karena kemudahan konfigurasi untuk aplikasi berbagai topologi jaringan, memiliki konsumsi daya yang relatif kecil serta jarak transmisi yang lebih jauh dibandingkan bluetooth dan wifi.

Sinyal EKG diperoleh dengan menempelkan beberapa elektroda apada tubuh pasien berdasar teknik sadapan segitiga Einthoven. Desain perangkat akuisi sinyal EKG terdiri dari rangkaian penguat diferensial/instrumentasi, driven right leg (DRL), filter analog (HPF dan LPF), penggeser sinyal (level shifter) dan penguat operasional. Sinyal analog hasil akuisisi dari masingmasing node sensor dikonversi menjadi bentuk digital oleh mikrokontroler dan selanjutnya data dikirim ke modul X-Bee untuk ditransmisikan ke node kordinator.

Secara rinci perancangan tersebut akan dijelaskan pada bagian berikutnya. Pada bagian II dijelaskan teori yang digunakan untuk menyelesaikan penelitian ini. Bagian III dijelaskan detail rancangan dan realisasi sistem. Pengujian dan diskusi dijelaskan pada bagian IV. Terakhir kesimpulan ada pada bagian $\mathrm{V}$.

\section{TEORI}

\subsection{Elektrokardiograf}

Elektrokardiograf (EKG) adalah instrumen medis yang digunakan untuk merekam aktivitas listrik jantung[2]. Rekaman aktivitas listrik tersebut disebut elektrokardiogram atau sinyal EKG. Bentuk suatu sinyal EKG normal dapat dilihat pada Gambar 1(a). Sadapan sinyal EKG dapat diperoleh dengan menempelkan beberapa transduser elektroda pada titik tertentu tubuh sesuai dengan teknik sadapan yang digunakan. Pada penelitian ini teknik sadapan yang digunakan adalah segitiga Einthoven dapat dilihat pada Gambar 1(b).

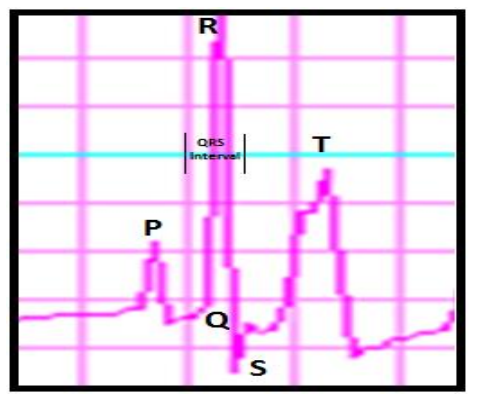

(a) 


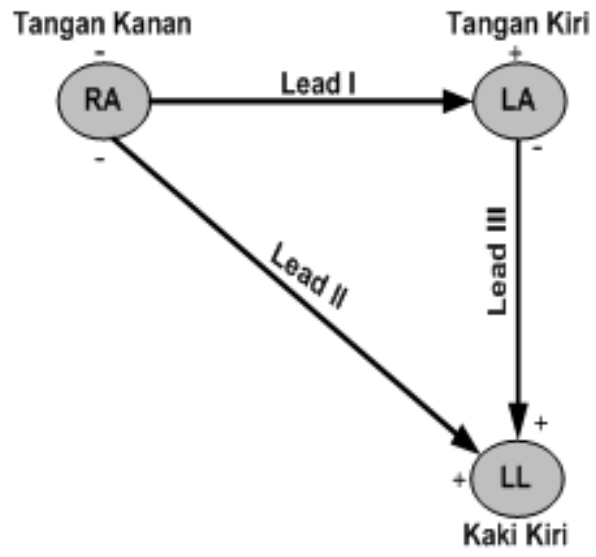

(b)

Gambar 1. (a) Sinyal EKG Normal (b) Sadapan Segitiga Einthoven

Teknik sadapan menggunakan segitiga Einthoven menghasilkan 3 buah sinyal EKG dari 3 sudut pandangan jantung yang berbeda. Tiga sinyal sadapan Einthoven disebut lead I, lead II dan lead III. Pada penelitian ini, sadapan yang diambil adalah lead I dimana elektroda positif ditempel pada tangan kiri dan elektroda negatif ditempel pada tangan kanan.

\subsection{X-Bee}

X-Bee adalah modul radio transceiver yang menggunakan protokol ZigBee IEEE 802.15.4 sebagai standar komunikasinya. X-Bee yang digunakan pada penelitian ini merupakan produksi dari Digi International (Gambar 2). Pemilihan modul X-Bee sebagai media transmisi data pada penelitian ini karena kemudahan konfigurasi untuk berbagai jenis topologi jaringan termasuk jaringan Mesh. X-Bee difungsikan untuk mentransmisikan data digital hasil konversi ADC. Antarmuka antara mikrokontroler dengan X-Bee menggunakan komunikasi serial USART. Konfigurasi pin mikrokontroler dengan X-Bee dapat dilihat pada Gambar 3.

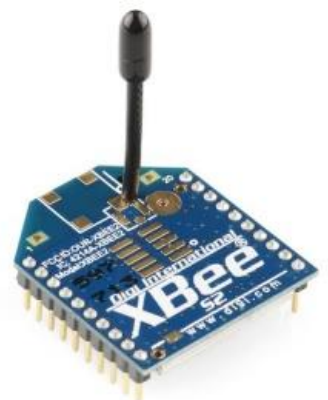

Gambar 2. Modul X-Bee Series 2[3]

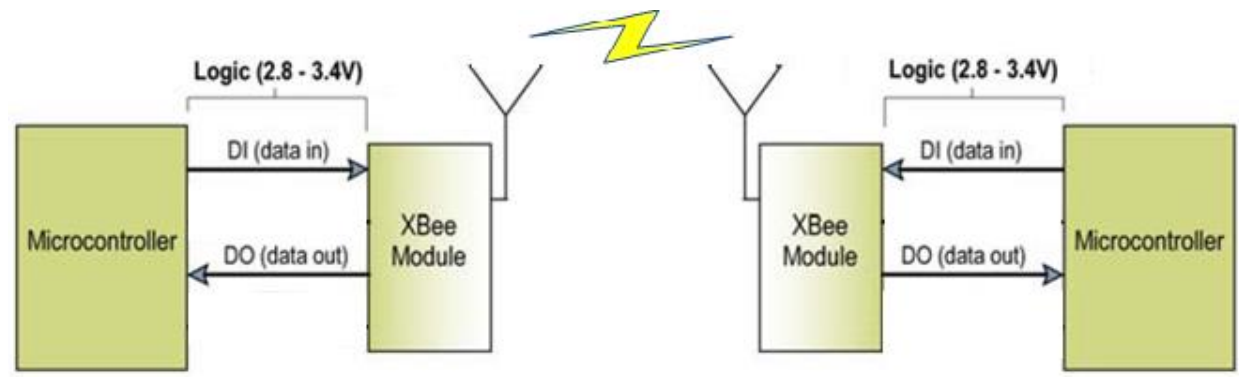

Gambar 3. Konfigurasi X-Bee dengan Mikrokontroler[4] 


\section{DESAIN SISTEM}

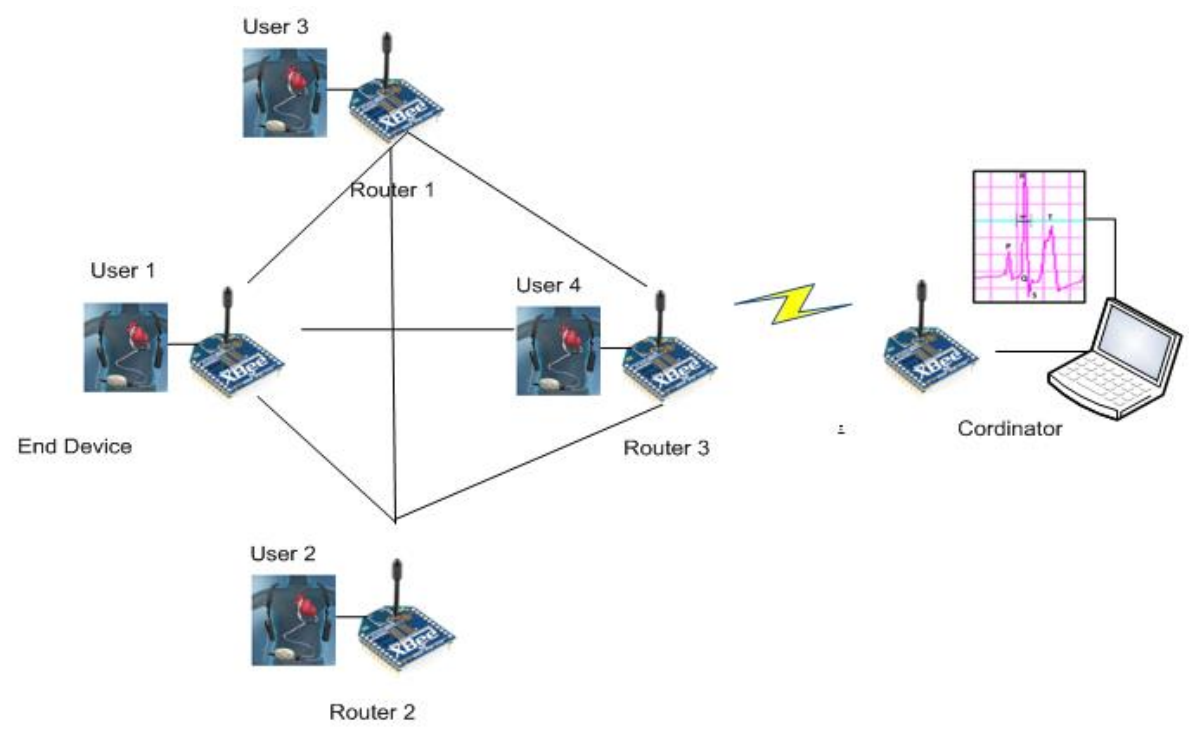

Gambar 4. Desain Sistem

Sistem yang direalisasikan pada penelitian ini terdiri dari 4 buah sensor node yang berfungsi untuk merekam sinyal EKG dan satu buah kordinator sebagai pusat pengolah dan penampil data sinyal. Topologi jaringan yang diterapkan adalah jaringan Mesh dimana pada topologi ini setiap node dapat saling berkomunikasi dengan node lain sehingga jika ada node yang terganggu atau tidak bekerja dapat dialihkan ke node lain.

Pada sisi pasien, perangkat EKG terhubung dengan mikrokontroler dan modul X-Bee. Data yang dari masing-masing pasien ditransmisikan ke X-Bee kordinator yang terhubung dengan sebuah komputer untuk kemudian diolah dan ditampilkan dalam bentuk grafik. Secara jelas sistem yang dibuat dapat dilihat pada Gambar 4.

\subsection{Perancangan Analog Front End (AFE) EKG}

Perangkat keras AFE EKG yang dibuat terdiri dari penguat instrumentasi, filter analog, penguat operasional dan level shifter. Elektroda positif dan negatif dihubungkan ke penguat Instrumentasi IC AD620 dengan besar penguatan 5 kali. Sinyal kemudian dilewatkan ke rangkaian filter HPF $0,05 \mathrm{~Hz}$ dan LPF $20 \mathrm{~Hz}$ untuk menghilangkan noise. Sinyal yang telah difilter dikuatkan kembali oleh penguat operasional dengan nilai gain 100 kali. Karena sebagian sinyal berada di level negatif maka semua komponen sinyal harus digeser pada level positif menggunakan level shifter. Gambar 5 berikut adalah skema blok AFE EKG.

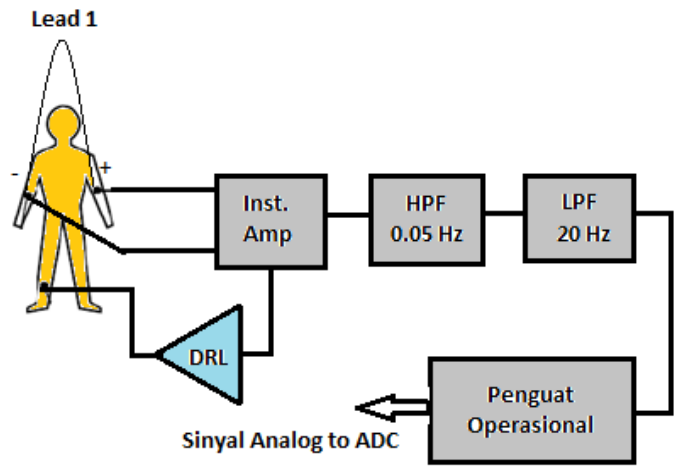

Gambar 5. Analog Front End EKG 


\subsection{Mikrokontroler}

Mikrokontroler pada setiap sensor node menjalankan fungsi membaca sinyal analog keluaran EKG kemudian mengirimkan data digital hasil konversi secara serial ke modul X-Bee. Pada penelitian ini, digunakan Arduino Nano sebagai pengontrol utama. Arduino Nano dipilih karena memiliki ukuran board yang lebih kecil dibandingkan dengan Arduino Uno sehingga dimensi perangkat dapat menjadi lebih kecil.

Melalui PIN A0, sinyal analog dikonversi oleh ADC internal mikrokontroler selanjutnya sinyal di-resampling menjadi $200 \mathrm{~Hz}$ sebelum dikirimkan secara serial ke modul X-Bee melalui PIN transmitter (Tx) pada Arduino. Data ADC yang dikirim, ditambahkan karakter (A, B, C dan D) untuk membedakan antara pasien yang satu dengan yang lain. Gambar 6 berikut adalah antarmuka antara Arduino Nano dengan X-Bee.

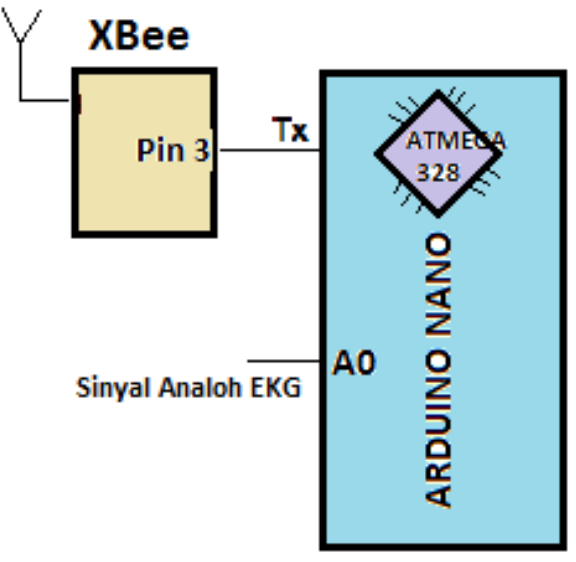

Gambar 6. Interface Arduino dan X-Bee

\subsection{Konfigurasi X-Bee}

Pengaturan parameter modul X-Bee agar dapat membentuk topologi Mesh dilakukan menggunakan aplikasi X-CTU. Pengalamatan (Addressing) merupakan parameter utama untuk dikonfigurasi. Selain itu, kecepatan transmisi data di-set 9600 Bps. Pengaturan alamat X-Bee untuk masing-masing node dapat dilihat pada Tabel 1 dibawah ini.

Tabel 1. Konfigurasi X-Bee

\begin{tabular}{|c|c|}
\hline \multicolumn{2}{|c|}{$\begin{array}{l}\text { X-Bee Kordinator set sebagai Coordinator } \\
\text { AT }\end{array}$} \\
\hline PAN ID & PAN ID semua node \\
\hline Alamat SH & DH router dan end device \\
\hline Alamat SL & DL router dan end device \\
\hline \multicolumn{2}{|c|}{$\begin{array}{l}\text { X-Bee Router (1,2 dan 3) set sebagai Router } \\
\text { AT }\end{array}$} \\
\hline PAN ID & PAN ID semua node \\
\hline Alamat DH & SH kordinator \\
\hline Alamat DL & SL kordinator \\
\hline \multicolumn{2}{|c|}{ X-Bee End Device set sebagai End Device AT } \\
\hline PAN ID & PAN ID semua node \\
\hline Alamat DH & SH kordinator \\
\hline Alamat DL & SL kordinator \\
\hline
\end{tabular}




\section{HASIL dan DISKUSI}

Untuk mengetahui performansi siistem yang telah dibuat maka dilakukan beberapa pengujian diantaranya pengujian pada bagian analog perangkat EKG dan pengujian bagian digital pada sisi penerima. Berikut ini adalah penjelasan hasil pengujian dan pembahasan untuk masingmasing skema pengujian tersebut.

\subsection{Pengujian EKG}

Hasil pengukuran sinyal analog keluaran AFE EKG dapat dilihat pada Gambar 7. AFE EKG dapat mengakuisisi sinyal EKG dengan baik, gelombang P-QRS-T terlihat sangat jelas dan bersih dari noise dengan nilai amplitudo pada kisaran $400 \mathrm{mV}$.

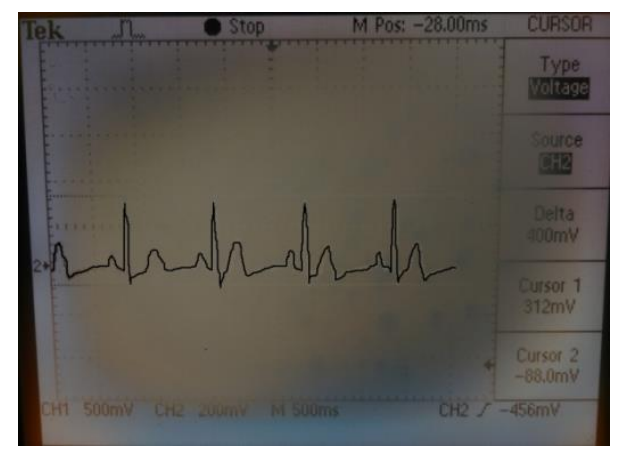

Gambar 7. Tampilan Sinyal Analog EKG

\subsection{Pengujian Data Digital}

Pada penelitian ini, aplikasi penampil grafik sinyal EKG belum dapat direalisasikan.Untuk melakukan validasi data yang dikirim Pengujian dilakukan dengan menggunakan aplikasi serial monitor yang dimiliki oleh X-CTU. Dari pengujian ini terlihat bahwa data dari setiap node diterima dengan baik. Karakter (ABCD) yang ada pada setiap data merupakan sign dari pasien mana data tersebut bersumber. Dari pengujian ini juga terlihat bahwa data yang diterima tidak selalu berurutan karena proses penjadwalan diatur secara otomatis oleh kordinator. Hasil pengujian data digital dapat dilihat pada Gambar 8.

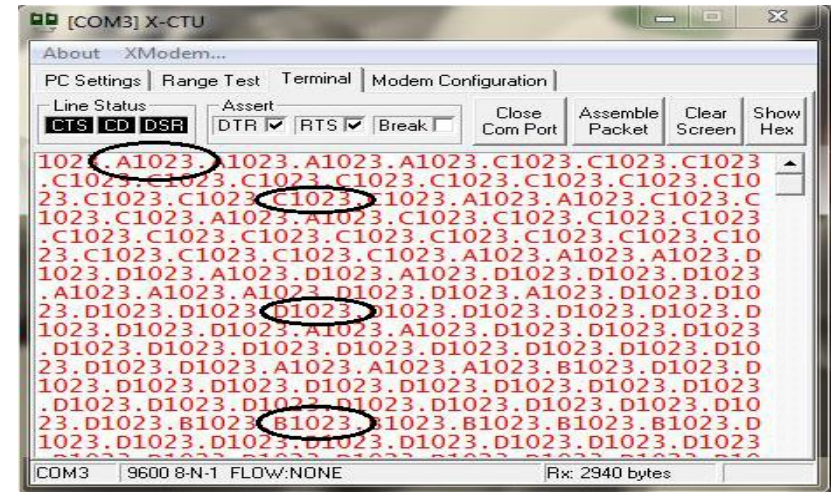

Gambar 8. Data Sinyal EKG dari Semua Node

\subsection{Pengujian Proses Routing}

Pada topologi jaringan Mesh erat kaitannya dengan skema routing atau pencarian jalur alternatif ketika terdapat kesalahan pada suatu node. Untuk mengetahui performansi skema jaringan yang telah diimplementasikan maka dibuat skema pengujian yang dapat dilihat pada Gambar 9. Pengujian dilakukan di ruang terbuka tanpa halangan (LOS). 


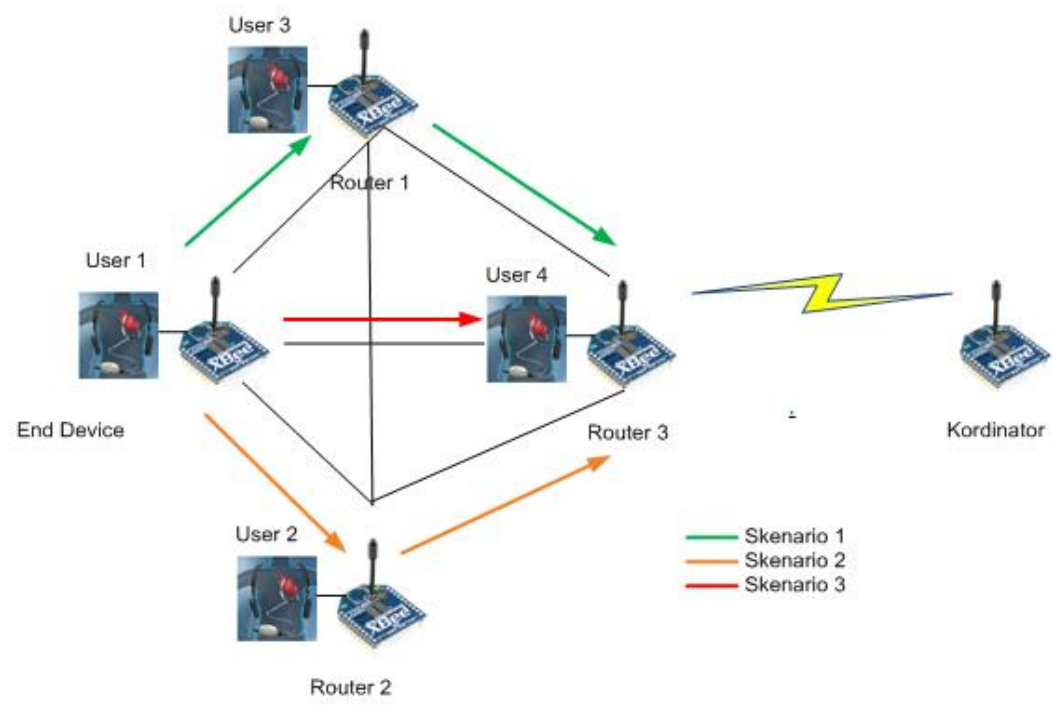

Gambar 9. Skema Pengujian Routing

Skenario dan hasil pengujian dapat dilihat pada Tabel 2 berikut.

Tabel 2. Hasil Pengujian Routing

\begin{tabular}{|c|l|l|}
\hline No & \multicolumn{1}{|c|}{ Skenario } & \multicolumn{1}{c|}{ Kondisi Pada Penerima } \\
\hline 1 & Node Router 1 Off & Data end device, router 2 dan 3 diterima \\
\hline 2 & Node Router 2 Off & Data end device, router 1 dan 3 diterima \\
\hline 3 & Node Router 1 dan 2 Off & $\begin{array}{l}\text { Data } \text { end device, router 3 diterima (catatan } \\
\text { ED masih dalam radius jangkauan router 3) }\end{array}$ \\
\hline
\end{tabular}

Dari Tabel diatas dapat disimpulkan bahwa proses routing dapat berjalan dengan baik. Ketika terdapat node yang tidak bekerja maka secara otomatis modul X-Bee menjalankan proses reroute atau penentuan ulang jalur transmisi.

\section{KESIMPULAN}

Setelah dilakukan implementasi sistem dan dilanjutkan dengan pengujian, diperoleh beberapa kesimpulan diantaranya:

1. Perangkat AFE EKG berhasil mengakuisisi sinyal EKG lead I ditandai dengan gelombang $\mathrm{P}-\mathrm{QRS}-\mathrm{T}$ yang terlihat jelas dan bersih dari noise.

2. Data digital yang dikirimkan dari seluruh node pasien dapat diterima dengan baik oleh kordinator berikut karakter tambahan (ABCD) sebagai penanda pasien.

3. Urutan data dari setiap node pasien bersifat acak. Proses penjadwalan dilakukan oleh protokol X-Bee.

4. Skema routing dapat berjalan dengan baik. Data sinyal masih terkirim meskipun terdapat node yang tidak bekerja.

5. Pada penelitian berikutnya, perlu dibuat aplikasi untuk menampilkan data sinyal EKG digital.

\section{DAFTAR PUSTAKA}

[1] S. Hadiyoso, Suci, "Multipoint to Point EKG Monitoring Berbasis ZigBee", Proceeding SNATI UII 2014, Yogyakarta, 2014. 
[2] Rizal, Achmad, 2013, "Instrumentasi Biomedis", Graha Ilmu, Bandung.

[3] XBee Pro S2, "Hardware XBee S2" [online] tersedia di http://www.mindkits.co.nz/store/communication/xbee-2mw-wire-antenna-series-2-zb [diakses tanggal 10 Maret 2014]

[4] Datasheet XBee, "Konfigurasi XBee," [online] Tersedia di https://www.sparkfun.com/datasheets/Wireless/Zigbee/XBee Datasheet.pdf [diakses 12 Maret 2014] 